\title{
Adoption of Opinion Mining in the Faculty Performance Evaluation System by the Students Using Naïve Bayes Algorithm
}

\author{
Francis F. Balahadia and Benilda Eleonor V. Comendador
}

\begin{abstract}
The paper promotes adoption of Opinion Mining in the faculty performance evaluation system by the students using Naïve Bayes algorithm. The study may help the university administrators to identify the strengths and weaknesses of the faculty members based on the textual evaluation made by the students written either in English or in Filipino language. The system provides graphical representation of the evaluation result in pie chart with the percentage of positive and negative feedback of the students. Based on the result of the survey, the respondents highly recommend the proposed system. Thus, the school administrators and educators will be more aware about the sentiments and concerns of the students. The reports generated from the developed system could be utilized to enhance the performance of the concerned faculty. In addition, the output from the objective evaluation of the teacher's performance could also be used as a basis for merit, awards, and/or promotion. Furthermore, the said innovation may encourage as well as improve fact-based decision making for university stakeholders.
\end{abstract}

Index Terms - Naïve Bayes algorithm, opinion mining, performance evaluation system.

\section{INTRODUCTION}

Universities are increasingly interested in using quality measures that provide evidence that can be used for the improvement of instruction and quality of education and other academic services. Evaluation is being used for informational feedback so that faculty might be more aware of the students' needs. The progress of the objectives of evaluation is to get feedback from the students about teaching efficiency and effectiveness of faculty. Students ask to complete course evaluations as part of the institution-wide assessment process.

One of the major academic goals for any university is to improve teaching quality. That is because many people believe that the university is a business and that the responsibility of any business is to satisfy their customers' needs. In this case university customers are the students. Therefore, it is important to reflect on students' attitudes to

Manuscript received October 30, 2014; revised March 2, 2015. This work was supported in part by the Polytechnic University of the Philippines.

Francis F. Balahadia is with the National University, Philippines (e-mail: balahadiafrancis@gmil.com).

Benilda Eleonor V. Comendador is with the Polytechnic University of the Philippines (e-mail: bennycomendador@yahoo.com). improve teaching quality. One way to improve teaching quality is to use traditional student evaluations [1]. Working towards improving teaching quality, it is important to know and considering students' opinions. Based on opinion extracted from students' reviews, previous work illustrates that the most important factor to students who is teaching the course [2].

Some instructors never look at student comments at all. In many cases, individual instructors do scan through at least some of their student comments to make their own interpretation [3]. According to a recent literature survey, many universities and colleges have no set policies on how to deal with student comments. "While many course evaluation forms include space for general comments, institutional guidelines are not always explicit with regard to how this data is to be managed" [4]. Such an unsystematic process makes it easy to miss the messages in a mass of student comments [3].

Online teachers' evaluation can be more efficient in integrating technique such as Opinion Mining. Opinion mining is a research subtopic of data mining which aims to automatically obtain useful knowledge in subjective texts [5]. This technique has been widely used in real-world applications such as e-commerce, business-intelligence, information monitoring and public polls [6]. Even in social media, opinion mining is useful some of them inspired by the research in characterizing events by the tweet around them like the work of $\mathrm{Hu}$ et al., modeling behavior patterns between events and tweets Ref. [7].

Opinion classification is a subtopic of opinion mining that classifies an opinionated document as expressing positive or negative. It is also commonly known as sentiment classification or document-level sentiment classification. It aims to find the general sentiment of the author in an opinionated text [6]. Opinion mining concerned with enabling system to determine opinion form text written in natural language by human [8]. Also it is mining data from subject text that can be divided by two: objectives and subjective text. Objective text is the objective description about some facts and events. Subjective text is the description of people's views of attitudes towards events and people.

Ref. [3] In the work done by eXplorance, the proponents made study regarding on how university considers the students feedback from their teacher using text analytics which focuses on identifying meaningful patterns or insights in form of keyword frequency or word clouds which are not powerful enough to hear the comprehensive message of student comments. Ref. [1] Consequently, Ei-Halees analyzed the user generated content of students to study the 
performance of certain course. He compared the performance of some course with each other by extracting opinion and visualize the extracted opinion which focuses in educational data and not on the teacher's performances in the classroom. Meanwhile, Song et al. proposed a method that uses user's opinion to develop and evaluate E-learning systems Ref. [9]. The authors used automatic text analysis to extract the opinions from the Web pages on which users are discussing and evaluating the services. Then, they used automatic sentiment analysis to identify the sentiment of opinions. They showed that opinions extraction is helpful to evaluate and develop E-learning system.

Teacher evaluation is widely understood to be the most effective tool to improve the quality of instruction in the schools [10]. Timely and accurate information is useful in virtually every stage of the decision-making process. Problems are identified when information reveals that some aspects of performance are less than desirable. The sooner accurate performance can be placed in the hands of decision-makers, the sooner problems can be corrected which may lessen the potentially undesirable or costly consequences to the organization [11].

In this light, the proponents focus their study in developing an application that can analyze the narrative evaluation of the students in addition to the numerical rating obtained by a faculty member during the performance evaluation period.

\section{THE PROPOSED SYSTEM}

\section{A. System Architecture}

Fig. 1 depicts the system architecture of the proposed system. The data used in the Online Teacher Evaluation (OTE) are extracted in the University Information System (UIS) using the OTE generator function. The data processed by the generator is in MySQL database format which is then forwarded to UIS for formatting and conversion into MySQL format before they can be uploaded in the OTE server.

The system can be accessed only by the university bonafide students, deans, program heads and coordinators using the username and password issued by the Information Technology Administrator. To preserve the student anonymity, the faculty performance evaluation is conducted in the academic laboratories during the scheduled class time while the teacher is out of the room.

The results are released to the faculty member after the semester has ended.

The broken line signifies the existing system that link to the proposed study. The students evaluate their teachers in numerical rating and qualitative scale using Online Teacher's Evaluation (OTE). The system focuses on analyzing the narrative responses of the students in addition to the numerical rating of the faculty. The said system consists of the three modules namely 1) Filtering Word Module 2) Sentiment Polarity Classification Module and 3) Summary and Visualization module. It handles the processing through the following procedures using Naïve Bayes Algorithm. First, from the OTE comment database server, it will classify the comments using Naïve Bayes classification techniques. It is a supervised learning and statistical technique as well as a statistical technique for classification [12]. The comments will undergo filtering to identify its polarity comments. Second, split sentences into single word, then compare the individual words of the sentence with database of words, while comparing, it will find the probability of the labels then it will compare the probability of positive and negative label. Additionally, the system will evaluate the polarity and proceed to the classification module then generate the summary and visualization result. Furthermore, the generated report will utilize by the top management, deans, department head, HR personnel, and IT personnel.

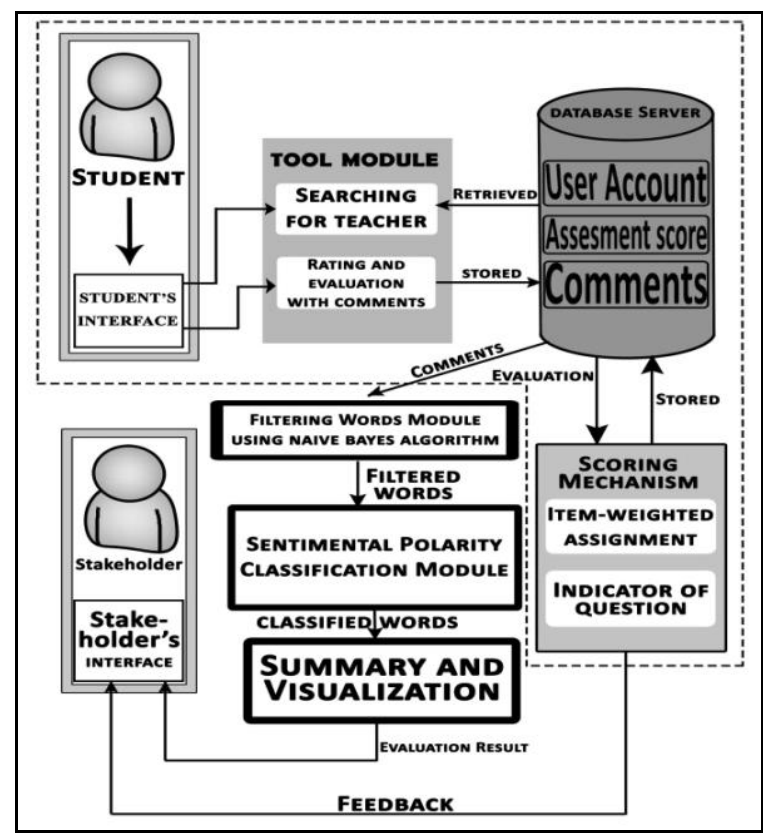

Fig. 1. Proposed system architecture.

TABLE I: REGISTERED USERS TYPE AS VIEWED BY THE SYSTEM ADMINISTRATOR

\begin{tabular}{|c|c|c|c|}
\hline EMPLOYEENO. & NAME & COLLEGE & USERTYPE \\
\hline $14-0001$ & Faculty1 & College of Computer Studies & Dean \\
\hline $14-0002$ & Faculty2 & College of Computer Studies & Department Head \\
\hline $14-0003$ & Faculty3 & College of Computer Studies & Faculty \\
\hline $14-0004$ & Faculty4 & College of Computer Studies & Faculty \\
\hline $14-0005$ & Faculty5 & College of Computer Studies & Faculty \\
\hline $14-0006$ & Faculty6 & College of Computer Studies & Faculty \\
\hline $14-0007$ & Faculty7 & College of Computer Studies & Faculty \\
\hline $14-0008$ & Faculty8 & College of Computer Studies & Faculty \\
\hline $14-0009$ & Faculty9 & College of Computer Studies & Faculty \\
\hline $14-00010$ & Faculty10 & College of Computer Studies & \\
\hline
\end{tabular}




\section{B. System Features}

The developed system has a feature that captures and stores in the database all possible participants. For anonymity, researchers used dummy faculty name (see Table II) as a sample. But in the actual output the system will display his real evaluation result.

The system has four types of users. It consists of the (1) System Administrator; (2) the top management; (3) the college dean and (4) the faculty members. The System Administrator has the highest right wherein he can identify the type of permission that he can give to access the system to all users (please see Table I). He can explore the log-in of the registered users, manage the account of the user, monitor and view the performance evaluation results. On the other hand, the top management users include the President, the Vice Presidents and the Human Resource personnel. The Human Resource personnel are in-charge in administering and keeping the records of the faculty performance evaluation.

The personnel in-charge can view the result of all colleges and generates summary report. The deans have an access to his faculty under his college to view the student comments and result.

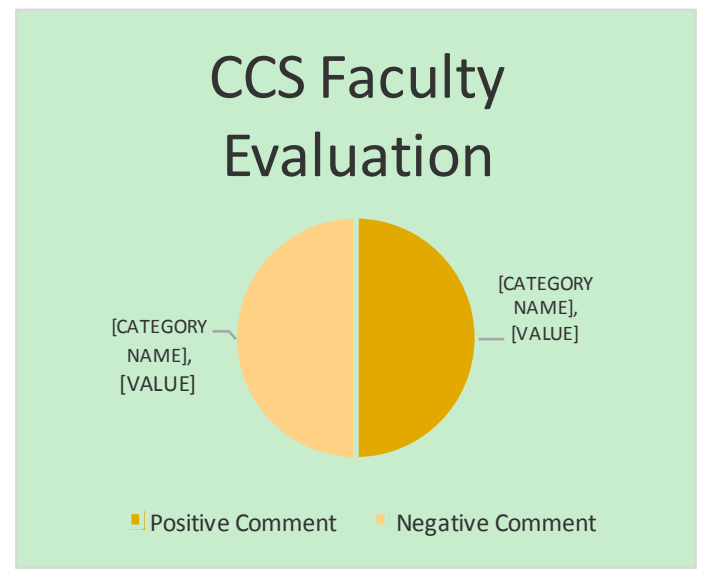

Fig. 2a. Result of the faculty evaluation in pie chart.

\begin{tabular}{|c|c|}
\hline School Year/Sem & $2014-2015-1$ \\
\hline Faculty ID & $13-0115$ \\
\hline College & College of Computer Studies \\
\hline \multicolumn{2}{|r|}{ Positive comment } \\
\hline \multicolumn{2}{|c|}{$\begin{array}{l}\text { He's really good in teaching his students. He knows how to make our } \\
\text { subject not boring. I just don't like it when he says "Hindi nyo alam?! } \\
\text { But I don't take it too seriously. :) }\end{array}$} \\
\hline \multicolumn{2}{|c|}{$\begin{array}{l}\text { He used to teach us very well. He is humorous professor, that's why } \\
\text { we're very entertained every time we have class. }\end{array}$} \\
\hline \multicolumn{2}{|c|}{$\begin{array}{l}\text { Congrats Sir. You have a very good in teaching and has a good sense } \\
\text { of humor. Keep up the good work Sir :)) }\end{array}$} \\
\hline \multicolumn{2}{|c|}{$\begin{array}{l}\text { He's so good! I don't know what to say! Basta magaling sya! Honesto! } \\
\text { Thanks sir. }\end{array}$} \\
\hline \multicolumn{2}{|c|}{ Negative comment } \\
\hline \multicolumn{2}{|c|}{ I can’t understand his diction. } \\
\hline \multicolumn{2}{|c|}{ He's having a hard time coming in class on time. } \\
\hline \multicolumn{2}{|c|}{$\begin{array}{l}\text { Madami magbigay ng reflection papers, not enough time para } \\
\text { makagawa yung students. }\end{array}$} \\
\hline
\end{tabular}

Fig. 2b. Result of the faculty evaluation in narrative response.

Meanwhile, the faculty members can only view his narrative evaluation result.
The students rate the faculty member based on the University evaluation procedures and associated instruments provide the framework for assessing teacher performance as it relates to the adopted performance criteria and also students will put comments on the given space provided as mentioned above the system only dealt in the quantitative scale evaluation.

The comments will be filtered to find the polarity in identifying comments, if it is positive or negative and it will generate visual representation of result through pie chart to show the polarity percentage. Once the polarity has been done it can view the entire positive or negative comments for each teacher.

The system accepts either English or Tagalog words. For visualization of the comment it uses tag cloud to view some of the comments used by the students before the user can see the whole narrative response of the students. Reports can be easily generated and be printed in pdf file for filling purposes. Fig. $2 \mathrm{a}$ and $2 \mathrm{~b}$ show the sample report which can be generated using the proposed system.

Another interesting feature of the proposed system is the provision to modify and update the school logo and other pertinent information about the school. This feature may facilitate the other educational institution to implement the said system to their community. Moreover, the study may also help the universities to gain more value from online course evaluations by considering the messages posted by the students. As such, the educational stakeholders will be more proactive in responding to the students' concerns.

\section{RESEARCH METHODS AND TECHNIQUES}

The study explores the concepts, theories, methodologies and technologies in designing the new online teachers' evaluation for the university. The study then presents the general requirements and issues in designing and deploying faculty evaluation in the web. The authors explored the available software tools, the existing hardware and infrastructure to develop the prototype. Afterward, they collaborate with the school stakeholders and educators then conduct a developmental research.

At the start of a semester, the authors gathered information that are being developed and utilized by the university administrators. The main function of the system is the polarity word dictionary which is constructed to filter and analyze some polarity words from the University Information System (UIS) and OTE comments server. The sentiment words are categorized into Tagalog words and English words. The authors chose 2000 positive words and 1000 negative words, but it does not indicate the words polarity strength. The authors applied a machine learning method which is Naïve Bayes. Naïve Bayes classifiers are widely used because of their simplicity and computational efficiency. It uses training methods consisting of relative-frequency estimation of words in a document as words probabilities and uses these probabilities to assign a category to the documents [13].

To test the effectiveness of the developed software, a pilot test was done on August 2014 to October 2014. The participants were twenty eighty (28) university's stakeholders from different colleges and offices of the University. 


\section{RESULTS AND DisCUSSIONS}

The research was conducted to assess the importance and the challenges encountered in the current online student's evaluation for teacher of the University as perceived by the respondents. In addition, it also sought to understand the acceptability of the developed software as it adapts the opinion mining in the Faculty Performance Evaluation System using Naïve Bayes Algorithm. The said system was evaluated by the respondents in terms of functionality, usability, reliability and performance.

Table II illustrates the summary of the respondents' level of acceptance of the developed system. It can be observed from the table that in terms of "Usability" the respondents said that the system is 'Highly Acceptable' which ranked first and obtained the mean response of 4.68. It is closely followed in the second rank by "Functionality" with a mean response of 4.63 verbally interpreted as 'Highly Acceptable'.

TABLE II: RESPONDENTS' LEVEL OF ACCEPTANCE OF THE DEVELOPED SYSTEM

\begin{tabular}{|l|c|c|c|}
\hline \multicolumn{1}{|c|}{ Criteria } & $\begin{array}{c}\text { Mean } \\
\text { Response }\end{array}$ & Interpretation & Rank \\
\hline Functionality & 4.63 & $\begin{array}{c}\text { Highly } \\
\text { Acceptable }\end{array}$ & 2 \\
\hline Usability & 4.68 & $\begin{array}{c}\text { Highly } \\
\text { Acceptable }\end{array}$ & 1 \\
\hline Reliability & 4.52 & $\begin{array}{c}\text { Highly } \\
\text { Acceptable }\end{array}$ & 4 \\
\hline Performance & 4.59 & $\begin{array}{c}\text { Highly } \\
\text { Acceptable }\end{array}$ & 3 \\
\hline Overall Mean & $\mathbf{4 . 6 1}$ & $\begin{array}{c}\text { Highly } \\
\text { Acceptable }\end{array}$ & \\
\hline
\end{tabular}

The third in the rank is "Performance" with a mean response of 4.59 interpreted as 'Highly Acceptable'. Furthermore, the "Reliability" received the fourth rank with a mean response of 4.52, which is interpreted as 'Highly Acceptable'. It can be concluded that the respondents considered the proposed system 'Highly Acceptable' as revealed by the overall mean of 4.61. Generally, the system's ratings in different questions are highly commendable by the respondents, as it offers the features it can provide to its user.

\section{CONCLUSIONS AND FUTURE WORKS}

Based on the evaluation made by the respondents on the proposed system, the researchers arrived to the following conclusions: Stakeholders highly agreed in the challenges of analyzing narrative responses of the students in the teacher's evaluation. For them, it may be one of the bases in crafting the faculty development plan to support their needs and be a better mentor to their students. The online performance evaluation of the teacher is very important because it is a tool for assessing their performance and addressing students' concerns.

After using the developed system, the respondents agreed that the system was able to perform the different functionality incorporated on it. In terms of usability, the users can easily navigate and operate the system conveniently. In terms of reliability, the system is able to identify the narrative response to its corresponding polarity (positive or negative). More importantly, it provides good visualization presentation of the evaluation result with percentage and can able to accept either English or Filipino language. With regards to its performance, the system can able to response several tasks in certain period of time. The developed system supports the students' desire to maintain quality education and be heard using online evaluation. It could be good system which may enable the academic managers to compile results, produce statistics, and generate reports of the narrative responses of the students which seems a laborious task. Conversely, the comments written by the students may help in studying the performance of individual instructors to identify their strength, potential and weaknesses. By applying the developed system, it may greatly help in evaluating the comments of the students during the faculty evaluation which is not typically given much attention by the deans/program coordinators.

\section{REFERENCES}

[1] A. El-Halees, "Mining opinions in user-generated contents to improve course evaluation," in Proc. International Journal on New Computer Architectures and their Application (IJNCAA), 2011, vol. 1, no. 4, pp. 1076-1085.

[2] P. Adamopoulos, "What makes a great mooc? An interdisciplinary analysis of students retention in online course," in Proc. the $34^{\text {th }}$ International Conference on Inofrmation Systems, ICIS, 2013.

[3] eXplorance 2013. Hear everything your student are saying: Why text analytics is essential for higher education. [Online]. Available: http://www.blackboard.com/resources/Learn/Partners/Whitepaper_He ar\%20Everything\%20Your\%20Students\%20Are\%20Saying.pdf

[4] P. Gravestock and E. Gregor-Greenleaf, "Student course evaluations: research, models and trends," Higher Education Quality of Ontario, p. 24, 2008.

[5] H. Song and T. Yao, "Active learning based corpus annotation," in Proc. IPS-SIGHAN Joint Conference on Chinese Language Processing, Beijing, China, August 2010, pp. 28-29.

[6] B. Pang and L. Lee. "Opinion mining and sentiment analysis," Information Retrieval 2, pp. 121-135, 2008.

[7] Y.-H. Hu et al., "What were the tweet about? Topical association between public events and twitter feeds," in Proc. ICWSM, Dublin, Ireland, 2012.

[8] L. Xia et al.," Improving patient opinion mining through multi-step classification," in Proc. LNCS, 2009, vol. 5729, pp. 70-76.

[9] D. Song, H. Lin, and Z. Yang, "Opinion mining in e-learning," presented at IFIP International Conference on Network and Parallel Computing Workshops, 2007.

[10] B. J. Koops and K. Winsor, "Creating a professional learning culture," The Journal of Education, vol. 186, no. 3, pp. 61-70.

[11] P. Lewis, S. Goodman, and P. Fandt, Management, Challenges for Tomorrow's Leaders, 4th ed. South-Western Thompson Learning, Canada, 2004.

[12] A. Mahendran, A. Duraiswamy, A. Reddy, and C. Gonsalves, "Opinion mining for text classification," International Journal of Scientific Engineering and Technology, vol. 2, issue 6, pp. 589-594, June 1, 2013.

[13] R. Du, R. Safavi-Naini, and W. Susilo, "Web filtering using text classification," IEEE Trans. on Neural Networks, vol. 4, pp. 570-578, July 1993.

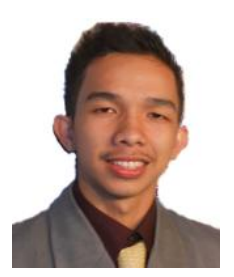

Francis F. Balahadia is a member of Science and Engineering Institutes, Philippine Computer Society and Philippine Society of It Educators. He earned the master of science degree in information technology from the Polytechnic University of the Philippine Graduate School in 2014. He is in the field of academe since 2011 and currently employed in National University (NU) College of Computer Studies as an assistant professor and an adviser of Junior Philippine Computer Society NU Chapter. Mr. Balahadia's study fields are in management information system, system analysis and design and some programming languages. 


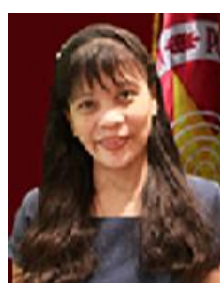

Benilda Eleonor V. Comendador was a grantee of the Japanese Grant Aid for Human Resource Development Scholarship (JDS) from April 2008 to September 2010. She obtained the master of science degree in global information telecommunication studies with majoring in project research at Waseda University, Tokyo Japan in 2010. She was commended for her exemplary performance in completing the said degree from JDS. She finished her master of science degree in information technology at Ateneo Information Technology Institute, Philippines in 2002.

Presently, she is the chief of the Open University Learning Management System (OU-LMS) and the program chair of the Master of Science in Information Technology (MSIT) of the graduate school of the Polytechnic University of the Philippines (PUP). She is an assistant professor and was the former chairperson of the Department of Information Technology of the College of Computer Management and Information Technology of PUP.
She attended various local and international computer related trainings and seminars. She was the country's representative to the Project Management Course in 2005, which was sponsored by the Center for International Computerization Cooperation (CICC) in Tokyo, Japan together with other 9 representatives from various ASEAN countries.

She presented several research papers in various international conferences and journals including the 1) 2009 IEICE Society Conference, Niigata Japan; 2) e-Case \& e-Tech in 2010 and in 2012 by International Conference on e-Commerce, e-Administration, e-Society, e-Education, and e-Technology, Macau; 3) International Journal of Arts \& Sciences IJAS Conference for Academic Disciplines in Las Vegas and 4)The Fifth International Conference on Mobile Computing and Ubiquitous Networking Seattle, U.S.A. 